\title{
A ADEQUAÇÃO DO CONSUMO DE ALIMENTOS DE ORIGEM ANIMAL E SUA RELAÇÃO COM RENDA FAMILIAR
}

SzARFARC, S. C. A adequação do consumo de alimentos de origem animal e sua relação com renda familiar. Rev. Saúde pủbl., S. Pallo, 13:26-31, 1979.

REsumo: Foi realizado estudo sobre adequação de consumo de proteinas de alto valor biológico e seu relacionamento com prȩ̧o e com renda familiar, em diferentes épocas. A diminulçáo de consumo de origem animal observada, foi causada, por uma modificação na distribuição orçamentária, na qual, a fração destinada à aquisição de carne, leite e ovos, em 1975, foi menor do que em 1969. O "Indice de Consumo de Proteinas de Origem Animal - ICPA", avaliado através da razâo entre renda familiar e custo dos alimentos de origem animal recomendados para a familia, é indicador eficiente do consumo desses alimentos $e$ indiretamente do estado nutricional. Para sua utilizaçāo é necessária a fixação de um ICPA crifico, que permita identificar as familias quanto à capacidade econômica, uma vez que a fração destinada a compra de alimentos de origem animal varia no decorrer do tempo.

Unitermos: Proteinas, consumo. Alimentos, custo. Renda familiar.

A importância dos alimentos de origem animal na dieta humana, como fonte de proteinas, é indiscutível. No entanto, a produção desses alimentos é de alto custo, o que, aliado ao baixo poder aquisitivo de populações em vias de desenvolvimento, limita o consumo a níveis abaixo dos recomendados. Em um levantamento de consumo, desenvolvido em 80 países e abrangendo $60 \%$ da população mundial, Autret ${ }^{1}$ verificou que, em apenas 19 deles, a principal fonte de proteina era constituida por alimentos de origem animal. A OMS * publicou, em 1973, a distribuição de calorias por nutrientes em 85 paises do mundo, onde verifica-se que à medida que o produto interno bruto por habitante cresce, aumenta o consumo de proteínas de alto valor biológico ${ }^{4}$. O mesmo trabatho sugere que a qualidade, mais do que a quantidade protéica, é afetada pela renda.

Tendo em vista a importância da renda no consumo de alimentos protéicos, Rueda Willianson ${ }^{6}$ propos a utilização de um "coeficiente protéico-econômico (CPE)" que consiste na razão entre renda familiar e custo dos alimentos portadores de proteína necessários para a família, como indicador indireto do estado nutricional.

Baseado nesse coeficiente, sugerimos a utilização de um novo indicador 5 "Indice de

* Do Departamento de Nutrição da Faculdade dẹ Saúde Públiça da USP - Ar. Dr. Arnaldo, i15 - 012555 - São Paulo, SP - Brasil. 
SZARFARC, S. C. A adequação do consumo de alimentos de origem animal e sua relação com renda familiar. Rev. Saude públ., S. Paulo, 13:26-31, 1979.

Consumo de Proteínas de Origem Animal - ICPA - " que se diferenciava do CPE pelo denominador no qual figura o custo dos alimentos de origem animal, fonte de proteina de alto valor biológico, recomendados para a familia.

A simplicidade da obtenção do ICPA, a par de sua efetividade como indicador direto do consumo de alimentos indispensáveis à manutençāo de um estado nutricional desejável, faz dele un instrumento útil. E no entanto necessário conhecer a variabiljdade no tempo dos componentes renda e custo de alimentos e a maneira pela qual 0 consumo efetivo do nutriente considerado é afetado por ambos. Assim, nesse estudo propusemo-nos a:

- analisar a variação de adequação de consumo de alimentos de origem animal, no decorrer do tempo;

- verificar a estabilidade, no tempo, do ICPA mínimo que corresponde a um consumo adequado de alimentos de origem animal.

\section{METODOLOGIA}

Esse estudo foi realizado na zona urbana de Cachoeira Paulista, cidade localizada no Vale do Paraíba, Estado de São Paulo, Brasil. A população urbana estimada para 1969,2 época em que foi testada a validade do ICPA, era de 12.720 habitantes, constituindo $70 \%$ do total populacional do Município; em $1975^{3}$ era de 13.000 habitantes, constituindo $75 \%$ do total populacional. A favela da Lagoa Seca abrigava $2,4 \%$ das familias en 1969 e $10 \%$ em 1975.

A amostra casual sistemática abrangen 208 familias em 1969 e 149 famílias em 1975. Os dados levantados através de inquérito domiciliar referiram-se a:

- consumo de alimentos de origem animal

- renda familiar

- composição familiar

- posse da residência (alugada, própria, em aquisição, cedida).
Os preços dos alimentos carne, leite e ovos foram obtidos nos locais de venda a varejo na época dos levantamentos (Tabela 1).

T A B E L A 1

Pregos médios de leite, carnes e ovos, Cachoeira Paulista, 1969 e 1975.

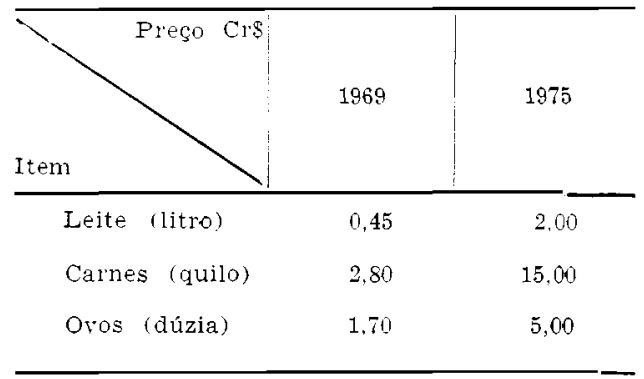

T A B E A 2

Custo das quantidades mensais minimas recomendadas de alimentos de origem animal, Cachoeira Paulista, 1969 e 1975.

\begin{tabular}{|c|c|c|}
\hline Preço Crs & 1969 & 1975 \\
\hline $0,--6 \mathrm{~m}$ & 3.00 & 82.50 \\
\hline $6-18 \mathrm{~m}$ & 3,00 & 33,00 \\
\hline $8--10 \mathrm{~m}$ & 13,50 & 83,00 \\
\hline $10--12 \mathrm{~m}$ & 15,00 & 39,00 \\
\hline $1-3 a$ & 12,00 & 31.50 \\
\hline $4--6 a$ & 14,40 & 31.50 \\
\hline $6 i-9 a$ & 17.00 & 38.70 \\
\hline 9 - $-11 a$ & 21.50 & 38,70 \\
\hline $11-\ldots 14 a$ & 24.00 & 47.40 \\
\hline$\sigma^{7} \quad 15-18 \mathrm{a}$ & 29,00 & 58,20 \\
\hline ㅇ $15,-18 \mathrm{a}$ & 29.00 & 50.10 \\
\hline$\sigma>18 \mathrm{a}$ & 22,50 & 52.80 \\
\hline$q>18 a$ & 17,50 & 41.70 \\
\hline Gestantes & 31.00 & 87,30 \\
\hline Nutrizes & 36,00 & 74,10 \\
\hline
\end{tabular}


SZARFARC. S. C. A adequação do consumo de alimentos de origem animal e sua relação com renda familiar. Rev. Saude públ., S. Paulo, 13:26-31, 1979.

Para garantir a presença de aninuácidos essenciais nas quantidades adequadas para a sintese protéica, parte da proteína deve ser fornecida como carne, leite e ovos. Tem sido adotado que $67 \%$, para grupos vulneráveis, e $50 \%$ para os não vulneráveis, da proteina recomendada, deve ser de origem animal. Aceito esse critério, foi calculado - custo desses alimentos (Tabela 2) utilizando as tabelas da recomendação de nutrientes do National Research Council',10, a tabela de composição de alimentos compilada pelo Departamento de Nutriçãos e preço local dos alimentos considerados (Tabela 1).

Com objetivo de minimizar esse custo fixamos o volume de leite de forma a fornecer todo o cálcio recomendado; 0 restante da proteína foi distribuida igualmente entre carnes e ovos.

Para cada família foi calculada a adequação de consumo dos alimentos considerados, através da relação: custo dos alimentos consumidos/custo dos alimentos recomendados.

O ICPA correspondente a $100 \%$ do consumo de alimentos de origem animal recomendados, que chamaremos de ICPA crítico, foi obtido através da estatística de regressão de uma reta, tendo sido correlacionado para cada familia amostrada a adequação de consumo e o ICPA.

O ICPA familiar foi calculado, pela relação:

rencla familiar - gastos para a posse da casa

custo dos alimentos considerados, recomendados para a familia.

\section{RESULTADOS E COMENTÁRIOS}

A distribuição de famílias segundo 0 nivel de adequação de consumo de proteínas de origem animal encontra-se na Fig. 1. A variação de consumo nas duas épocas estudadas sugere uma tendência de diminuição de ingestão de carne, leite e ovos. Em 1969, 50\% da população apresentou-se con consumo insuficiente. Esse valor elevou-se para $69 \%$ em 1975 , sendo necessário acrescentar que do total amostrado, $28 \%$ das familias consumiram menos do que $20 \%$ do recomendado.

O leite, por ser insubstituivel na alimentaçāo dos lactentes, por ser a fonte de proteina de mais baixo custo (Tabela 1) e ainda por ser produto base da economia de Cachoeira Paulista', mereceu uma análise à parte. Na Tabela 3 , temos a distribuição de famílias que o consumiram ou não, na quantidade adequada.

Da mesma forma que os alimentos de alto valor biológico em geral, houve um decréscimo no consumo do leite.
T A B E L A 3

D)stribuição de famílias, segundo adequação de consumo do leite. Cachoeira Paulista, 1969 e 1975.

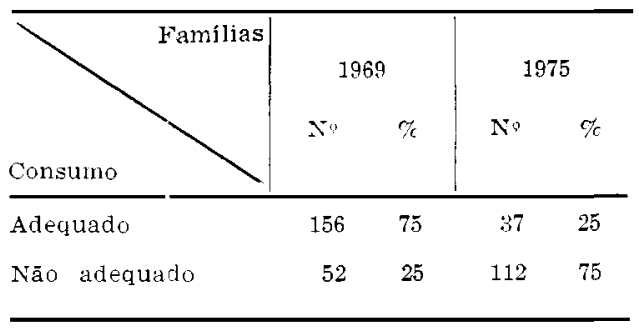

Enbora Cachoeira Paulista seja grande produtora de leite, a disponibilidade deste no mercado varejista diminuiu em função de um aumento da exportação do mesmo. Em 1969, todo o leite consumido na cidade era oriundo de produção local, em 1975 apenas $15 \%$ teve essa origem ${ }^{3}$. Com relação à distribuição de leite em pó, pelo Centro de Saúde, esse serviço, em 1969, apresentava-se mais regular e beneficiava maior número de famílias do que em 1975.

Na Fig. 2 temos a distribuição das familias segundo níveis de ICPA. Não foi 
SZARFARC, S. C. A adequação do consumo de alimentos de origem animal e sua relação com renda familiar. Rer. Saude públ., S. Paulo. 13:26-31, 1979.

observada diferença significante na proporção de ICPA nos dois períodos, a não ser no nível mais baixo, no qual, em 1969 , foram encontradas $14 \%$ das familias e, em 1975, 3\%. Sendo o ICPA obtido através da razāo entre renda (descontado o dispendido para posse da residência) e custo dos alimentos de origem animal recomendados para a familia, pode-se dizer que nos periodos observados, os aumentos do custo da proteina e do ingresso da família foram proporcionais. Desde que houve diminuição no consumo, esta diminuição

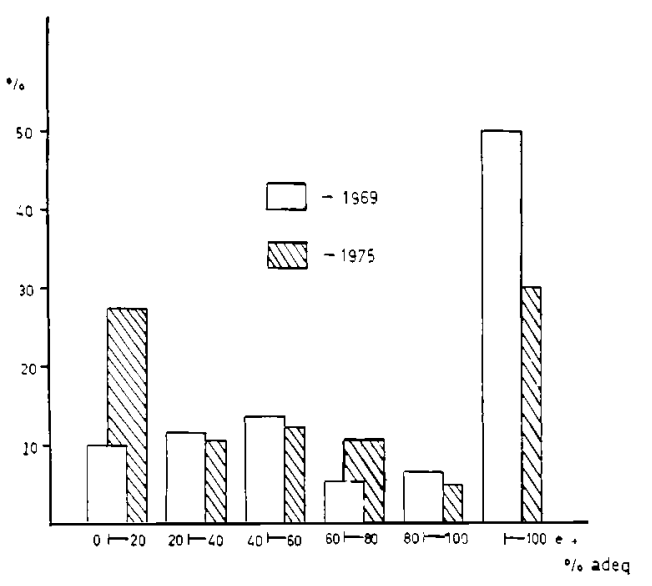

Fig. 1 - Distribuição de famílias segundo a adequação de consumo de alimentos de origem animal, Cachoeira Paulista, 1969 e 1975.

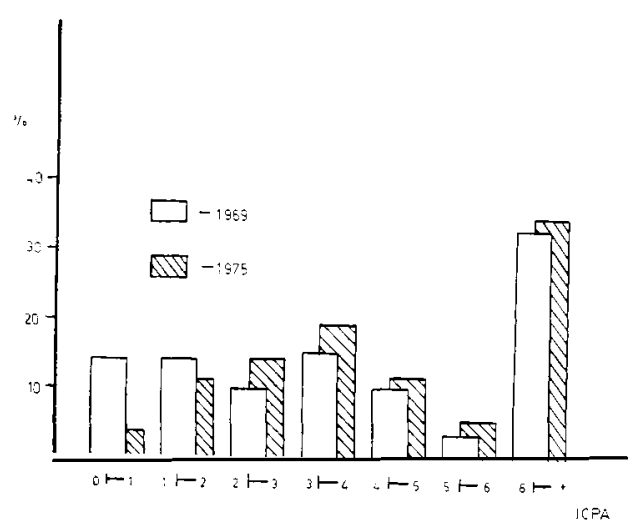

Fig. 2 - Distribuição das famílias segundo o valor ICPA, Cachoeira Paulista, 1969 e 1975. pussivelmente ć função de uma modificação na distribuição orçamentária onde a fração destinada à aquisição de proteinas de alto valor biológico foi menor.

A determinação do ICPA crítico visa identificar famílias com e sem capacidade econômica de adquirir os alimentos de origem animal. Esse valor mostrou ser variável no decorrer do tempo. Embora não signifique que a familia que tem capacidade financeira ingira esses alimentos, a relação positiva entre renda e consumo é nítida. Em 1969 (Fig. 3) o valor do ICPA crítico encontrado foi 4,1 . A proporção de famílias com ICPA abaixo desse valor foi $46 \%$ e $50 \%$ a percentagem de familias com ingestão inadequada.

Em 1975, o valor crítico do ICPA passou a 5,8. A proporção de famílias com ICPA abaixo desse limite foi $37 \%$ e $31 \%$ a proporção de famílias com inadequação de consumo dos alimentos considerados.

A utilização do "Índice de Consumo de Proteinas de Origem Animal", como indicador indireto do estado nutricional, é eficaz. No entanto, como o ICPA crítico, padrão para avaliaçăo dos resultados encontrados, é variável no tempo, é necessário reavaliá-lo sempre que utilizado.

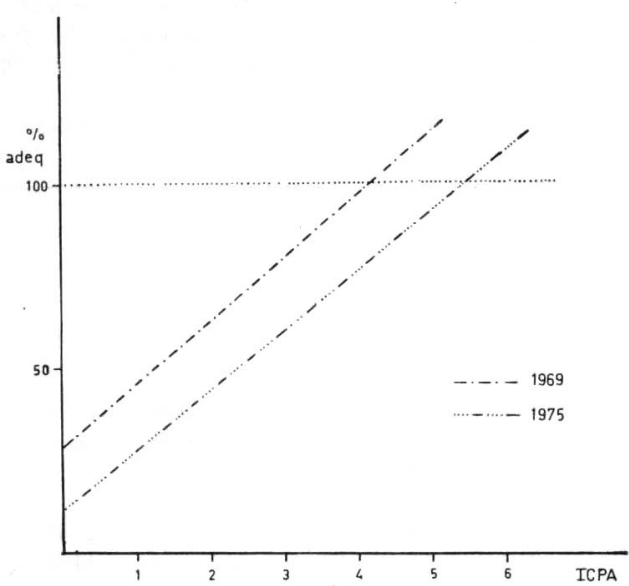

Fig. 3 - Reta de regressão utilizando adequação de consumo de proteinas de origem animal em função do ICPA - Cachoeira Paulista, 1969 e 1975. 
SZARFARC, S. C, A adequação do consumo de alimentos de origem animal e sua relação com renda familiar. Rev. Saúde públ., S. Paulo, 13:26-31, 1979.

\section{CONCLUSÕES}

Do estudo do consumo de alimentos de origem animal e seu relacionamento com custo dos mesmos e renda familiar, realizado em 1969 e em 1975, na zona urbana de Cachoeira Paulista, concluimos:

- A proporção de familias com consumo adequado de alimentos de origem animal diminuiu no intervalo de tempo considerado. (Fig. 1)

- O aumento do preço da proteína de origem animal $e$ o aumento do ingresso familiar, avaliado através do ICPA, fo- ram proporcionais no decorrer $\mathrm{d}$ ) tempo. (Fig. 2)

- O valor do ICPA crítico variou de 4,1 em 1969 a 5,8 em 1975. (Fig. 3)

- A avaliação do consumo de proteínas de alto valor biológico e a avaliação indireta do estado nutricional feita através do "indice de Consumo de Proteinas de Origem Animal", são eficientes e econômicas. Exigem, no entanto, para sua aplicação, o levantamento concomitante da distribuição orçamentária básica que permitirá a fixação do ICPA crítico.

RSPUB $9 / 443$

SZARFARC, S. C. IThe determination of adequate animal protein consumption and its relation to family income] Rev. Saúde públ., S. Paulo, 13:26-31, 1979.

ABSTRACT: Adequate consumption of proteins of high biological value is related to cost and family income at different periods of time. The decrease of consumption of animal protein observed was caused by alterations in family budgets in which the portion allotted for buying meat, milk, and eggs was smaller in 1975 than in 1969. The "Index of Animal Protein Consumption (ICPA)," estimated by the ratio - family income/cost of recommended animal foodstuff - is an efficient indicator of the consumption of such foodstuff and, indirectly, of nutritional status. Its use, however, implies the classification of families as to their economic status because the portion of the butget allotted for buying animal foodstuff varies according to the period of time considered.

UNITERMS: Proteins, consumption. Food, cost. Family income.

\section{REFERENCIAS BIBLIOGRÁFICAS}

1. AUTRET, M. et al. apud. TAGLE, A. Nutricion, 73 Santiago, Chile, Impresores Jerba, 1973.

2. CACHOEira PAULista. São Paulo, 1969. [Relatório do Estágio de Campo Multiprofissional - Faculdade de Saúde Pública, USP, 1969 - mimeografado].

3. CACHOEIRA PAULISTA. São Paulo, 1977. [Relatório do Estágio de Campo Multj. profissional - Faculdade de Saúde Pública, USP, 1975-1976 - mimeografado].

4. COMITE ESPECIAL MIXTO FAO/OMS DE EXPERTOS EN NECESIDADES DE ENERGIA $Y$ DE PROTEINAS, Roma, 1971. Informe. Ginebra, OMS, 1973. (OMS - Ser. Inf. tecn., 522).

5. CORNBLUTH, S. Avaliação nutricional indireta da populacão urbana de Ca- 
SZARFARC, S. C. A adequação do consumo de alimentos de origem animal e sua relação com renda familiar. Rev. Saúde puibl., S. Paulo, 13:26-31, 1979.

choeira Paulista, através da renda familiar. São Paulo, 1970. [Dissertação de Mestrado - Faculdade de Saúde Pública da USP].

6. RUEDA WILLIANSON, R. E1 coeficiente protéjco-econômico. (Apresentado a Reunjão Anual PAG - OMS, Ginebra, 1965).

7. SECRETARIA DE ECONOMIA E PLANEJAMENTO DO ESTADO. Departamento de Estatistica. Conheça seu municipio: região do Vale do Paraíba. São Paulo, 1974. v. 3, t.1.

8. UNIVERSIDADE DE SAO PAULO. Faculdade de Saúde Pública. Departamento de Nutrição. Tabela de composicão química dos alimentos; Compilacão de varias tabelas nacionais e estrangeiras. São Paulo, 1971 [mimeografado]

9. U.S. National Academy of Sciences. Recommended daily dietary allowances; revised, 1973. Chicago, Ill., 1973/1974.

10. U.S. National Academy of Sciences. Recommended dietary allowances; report 7th ed. Washington, D. C., 1968.

Recebido para publicação em 06/07/1978 Aprovado para publicação em 09/11/1978

\section{CURSO DE ESPECIALIZAÇÃO DE ENTOMOLOGIA EPIDEMIOLÓGICA}

Dando prosseguimento à série de cursos de entomologia médica, criados em 1950 pelo Prof. Lane, o Departamento de Epidemiologia da Faculdade de Saúde Pública da Universidade de São Paulo, fará realizar o VII Curso de Especialização de Entomologia Epidemiológica (correspondente ao 19\% curso sobre a especialidade), sob a orientação do Prof. Oswaldo Paulo Forattini. Adaptado a partir de 1970, esse Curso, atualmente em nivel de especialização, é oferecido anualmente a profissionais de nivel superior, que pretendem se dedicar à entomologia de interesse médico e/ou atividades de epidemiologia no campo das doenças veiculadas por artrópodes. Consta de 500 horas, em tempo integral, com atividades didáticas formais e práticas de laboratório, campo e insetário.

As inscrições estarão abertas no periodo de 15 de maio a 15 de julho de 1979, na Seção de Alunos da Faculdade de Saúde Pública da USP, Av. Dr. Arnaldo, 715, S. Paulo. 